\title{
Bounds on the first leap Zagreb index of trees
}

\begin{abstract}
Dehgardi N. ${ }^{1}$, Aram H. ${ }^{2, 凶}$
The first leap Zagreb index $L M 1(G)$ of a graph $G$ is the sum of the squares of its second vertex degrees, that is, $L M_{1}(G)=\sum_{v \in V(G)} d_{2}(v / G)^{2}$, where $d_{2}(v / G)$ is the number of second neighbors of $v$ in $G$. In this paper, we obtain bounds for the first leap Zagreb index of trees and determine the extremal trees achieving these bounds.

Key words and phrases: tree, first leap Zagreb index, Zagreb index.
\end{abstract}

\footnotetext{
${ }^{1}$ Department of Mathematics and Computer Science, Sirjan University of Technology, Sirjan, Iran

2 Department of Mathematics, Gareziaeddin Center, Khoy Branch, Islamic Azad University, Khoy, Iran

$\triangle$ Corresponding author

E-mail: n.dehgardiesirjantech.ac.ir(DehgardiN.), hamideh.aramegmail.com (Aram H.)
}

\section{Introduction}

Let $G$ be such a simple graph with vertex set $V$ and edge set $E$. The order $|V|$ of $G$ is denoted by $n$ and the size $|E|$ of $G$ is denoted by $m$. The degree of a vertex $v$ in $G$ is the number of edges incident to $v$ and is denoted by $d(v / G)$. The maximum degree of a graph $G$ are denoted by $\Delta=\Delta(G)$. The distance $d_{G}(u, v)$ between any two vertices $u$ and $v$ of a graph $G$ is equal to the length of a shortest path connecting them. For a vertex $v \in V(G)$ and a positive integer $k$, the open $k$-neighborhood of $v$ in the graph $G$, denoted by $N_{k}(v / G)$, is defined as $N_{k}(v / G)=\{u \in V(G): d(u, v)=k\}$. The $k$-distance degree of a vertex $v$ in $G$, denoted by $d_{k}(v / G)$, is the number of $k$-neighbors of the vertex $v$ in $G$, i.e., $d_{k}(v / G)=\left|N_{k}(v / G)\right|$. Evidently, $d_{1}(v / G)=d(v / G)$ for every $v \in V(G)$.

A leaf of a tree $T$ is a vertex of degree one and a stem is a vertex adjacent to a leaf. A rooted tree is a tree having a distinguished vertex $\omega$, called the root. If $v$ is a vertex in $T$ other than the root, the parent of $v$ is the vertex connected to $v$ on the path to the root. A spider is a tree with at most one vertex of degree greater than 2 , called the center of the spider. If there is no vertex of degree greater than two, then any vertex can be considered as the center. A leg of the spider is a path from the center to a vertex of degree one. Thus, a star with $k$ edges is a spider with $k$ legs, each of length 1 , and the path is a spider with 1 or 2 legs.

Two of the oldest bond-additive invariants are Zagreb indices which were introduced by I. Gutman and N. Trinajstić in [15]. For a graph G, the first and second Zagreb indices are defined as

$$
M_{1}=M_{1}(G)=\sum_{v \in V(G)} d(v / G)^{2} \quad \text { and } \quad M_{2}=M_{2}(G)=\sum_{u v \in E(G)} d(u / G) d(v / G),
$$

respectively. For more properties of Zagreb indices, see the surveys [4,14]. 
In recent years, some novel variants of topological indices have been put forward, such as Zagreb coindices [3,9,13], general Zagreb index [12], entire Zagreb indices [2, 16], augmented Zagreb index [1, 6, 11], Lanzhou index [8,21], Mostar index [7, 10], revised Szeged index [5, 18], etc.

A.M. Naji, N.D. Soner and I. Gutman [17] extended the concept of Zagreb index to the second vertex degrees. For a graph $G$, the first, second, and third leap Zagreb indices are defined as follows

$$
\begin{gathered}
L M_{1}=L M_{1}(G)=\sum_{v \in V(G)} d_{2}(v / G)^{2}, \quad L M_{2}=L M_{2}(G)=\sum_{u v \in E(G)} d_{2}(u / G) d_{2}(v / G), \\
L M_{3}=L M_{3}(G)=\sum_{v \in V(G)} d(v / G) d_{2}(v / G) .
\end{gathered}
$$

For more information about leap Zagreb indices, see for example [20,22].

In this paper, we focus on the first leap Zagreb index. We obtain lower bounds on the first leap Zagreb index and characterize the extremal trees achieving these bounds. We also present upper bounds for the first leap Zagreb index of trees.

\section{Bounds on first leap Zagreb index of trees}

In this section, we present sharp lower bounds for the first leap Zagreb index of trees in terms of their order and maximum degree, and characterize all extremal trees.

Throughout this section, $T$ denotes a rooted tree with root $\omega$, where $\omega$ is a vertex of maximum degree and $N(\omega)=\left\{w_{1}, w_{2}, \ldots, w_{\Delta}\right\}$.

We start with some lemmas.

Lemma 1. Let $T$ be a tree of order $n$ with maximum degree $\Delta$. If $T$ has a vertex $u$ of degree at least three, that is in maximum distance from $\omega$, then there is a tree $T^{\prime}$ of order $n$ with maximum degree $\Delta$ such that $L M_{1}\left(T^{\prime}\right)<L M_{1}(T)$.

Proof. Let $u \neq \omega$ be a vertex of $T$ with $d(u / T)=\alpha \geq 3$ and let $N_{T}(u)=\left\{u^{\prime}, x_{1}, x_{2}, \ldots, x_{\alpha-1}\right\}$, where $u^{\prime}$ is the parent of $u$. Assume $d\left(u^{\prime} / T\right)=\beta$. We consider the following cases.

Case 1. All neighbors of $u$ except $u^{\prime}$ are leaves.

Subcase 1.1. $u^{\prime}$ is adjacent to a leaf $y$.

Let $T^{\prime}$ be the tree obtained from $T-x_{1}$ by attaching the edge $y x_{1}$. Clearly, $T^{\prime}$ is a tree of order $n$ with $\Delta(T)=\Delta\left(T^{\prime}\right)$. Also $d_{2}(u / T)=d_{2}\left(u / T^{\prime}\right), d_{2}\left(u^{\prime} / T\right)=d_{2}\left(u^{\prime} / T^{\prime}\right), d_{2}(y / T)=$ $d_{2}\left(y / T^{\prime}\right), d_{2}\left(x_{1} / T\right)=d_{2}\left(x_{1} / T^{\prime}\right)+\alpha-2=\alpha-1$, and $d_{2}\left(x_{i} / T\right)=d_{2}\left(x_{i} / T^{\prime}\right)+1=\alpha-1$ for $2 \leq i \leq \alpha-1$. By definitions we have

$$
\begin{aligned}
L M_{1}\left(T^{\prime}\right)-L M_{1}(T) & =\sum_{v \in V\left(T^{\prime}\right)} d_{2}\left(v / T^{\prime}\right)^{2}-\sum_{v \in V(T)} d_{2}(v / T)^{2} \\
& =\sum_{i=2}^{\alpha-1} d_{2}\left(x_{i} / T^{\prime}\right)^{2}+d_{2}\left(x_{1} / T^{\prime}\right)^{2}-\sum_{i=2}^{\alpha-1} d_{2}\left(x_{i} / T\right)^{2}-d_{2}\left(x_{1} / T^{\prime}\right)^{2} \\
& =(\alpha-2)(\alpha-2)^{2}+1-(\alpha-2)(\alpha-1)^{2}-(\alpha-1)=-2 \alpha^{2}+6 \alpha-4<0 .
\end{aligned}
$$


Subcase 1.2. $u^{\prime}$ has no leaf neighbor.

Let $T^{\prime}$ be the tree obtained from $T-x_{1}$ by attaching the edge $x_{1} x_{2}$. Then $d_{2}\left(u^{\prime} / T\right)=$ $d_{2}\left(u^{\prime} / T^{\prime}\right)+1=k+\alpha-1$ for $k \geq \beta-1, d_{2}(u / T)=d_{2}\left(u / T^{\prime}\right)-1=\beta-1, d_{2}\left(x_{i} / T\right)=$ $d_{2}\left(x_{i} / T^{\prime}\right)+1=\alpha-1$ for $2 \leq i \leq \alpha-1$, and $d_{2}\left(x_{1} / T\right)=d_{2}\left(x_{1} / T^{\prime}\right)+\alpha-2=\alpha-1$. Hence,

$$
\begin{aligned}
L M_{1}\left(T^{\prime}\right)-L M_{1}(T)= & \sum_{v \in V\left(T^{\prime}\right)} d_{2}\left(v / T^{\prime}\right)^{2}-\sum_{v \in V(T)} d_{2}(v / T)^{2} \\
= & \sum_{i=2}^{\alpha-1} d_{2}\left(x_{i} / T^{\prime}\right)^{2}+d_{2}\left(u / T^{\prime}\right)^{2}+d_{2}\left(u^{\prime} / T^{\prime}\right)^{2}+d_{2}\left(x_{1} / T^{\prime}\right)^{2} \\
& \quad-\sum_{i=2}^{\alpha-1} d_{2}\left(x_{i} / T\right)^{2}-d_{2}(u / T)^{2}-d_{2}\left(u^{\prime} / T\right)^{2}-d_{2}\left(x_{1} / T^{\prime}\right)^{2} \\
& =\sum_{i=2}^{\alpha-1}\left[(\alpha-2)^{2}-(\alpha-1)^{2}\right]+\beta^{2}-(\beta-1)^{2}+(\alpha+k-2)^{2} \\
& -(\alpha+k-1)^{2}+1-(\alpha-1)^{2} \\
= & (\alpha-2)(-2 \alpha+3)+2 \beta-1-2(\alpha+k)+3-\alpha^{2}+2 \alpha \\
= & -2 \alpha^{2}+7 \alpha-6+2 \beta-1-2 \alpha-2 k+3-\alpha^{2}+2 \alpha \\
\leq & -3 \alpha^{2}+7 \alpha-4<0 .
\end{aligned}
$$

Case 2. $u$ is adjacent to a leaf $x_{1}$ and $u y_{1} y_{2} \ldots y_{\ell}$ is a path in $T$ for $\ell \geq 2$ such that $y_{1}=x_{2}$.

If $u^{\prime}$ is a stem, then the result is immediate as in Case 1 . So assume that $u^{\prime}$ is not a stem. Let $T^{\prime}$ be the tree obtained from $T-x_{1}$ by attaching the edge $y_{\ell} x_{1}$. Then $d_{2}\left(u^{\prime} / T\right)=$ $d_{2}\left(u^{\prime} / T^{\prime}\right)+1=k+\alpha-1$ for $k \geq \beta-1, d_{2}(u / T)=d_{2}\left(u / T^{\prime}\right), d_{2}\left(x_{1} / T\right)=d_{2}\left(x_{1} / T^{\prime}\right)+\alpha-2$, and $d_{2}\left(x_{i} / T\right)=d_{2}\left(x_{i} / T^{\prime}\right)+1$, for $2 \leq i \leq \alpha-1$.

If $\ell \geq 3$, then $d_{2}\left(y_{\ell-1} / T\right)=d_{2}\left(y_{\ell-1} / T^{\prime}\right)-1=1$ and

$$
\begin{aligned}
L M_{1}\left(T^{\prime}\right)-L M_{1}(T)= & \sum_{v \in V\left(T^{\prime}\right)} d_{2}\left(v / T^{\prime}\right)^{2}-\sum_{v \in V(T)} d_{2}(v / T)^{2} \\
= & \sum_{i=2}^{\alpha-1} d_{2}\left(x_{i} / T^{\prime}\right)^{2}+d_{2}\left(u^{\prime} / T^{\prime}\right)^{2}+d_{2}\left(y_{\ell-1} / T^{\prime}\right)^{2}+d_{2}\left(x_{1} / T^{\prime}\right)^{2} \\
& \quad-\sum_{i=2}^{\alpha-1} d_{2}\left(x_{i} / T\right)^{2}-d_{2}\left(u^{\prime} / T\right)^{2}-d_{2}\left(y_{\ell-1} / T\right)^{2}-d_{2}\left(x_{1} / T^{\prime}\right)^{2} \\
= & \sum_{i=2}^{\alpha-1}\left[\left(d_{2}\left(x_{i} / T\right)-1\right)^{2}-d_{2}\left(x_{i} / T\right)^{2}\right]+(\alpha+k-2)^{2}+4+1 \\
& -(\alpha+k-1)^{2}-1-(\alpha-1)^{2} \\
= & \sum_{i=2}^{\alpha-1}\left[\left(d_{2}\left(x_{i} / T\right)-1\right)^{2}-d_{2}\left(x_{i} / T\right)^{2}\right]-2 k-\alpha^{2}+6<0 .
\end{aligned}
$$

Now, if $\ell=2$, then $d_{2}\left(y_{\ell-1} / T\right)=d_{2}\left(y_{\ell-1} / T^{\prime}\right)$, and so we obtain

$$
\begin{aligned}
L M_{1}\left(T^{\prime}\right)-L M_{1}(T) & =\sum_{v \in V\left(T^{\prime}\right)} d_{2}\left(v / T^{\prime}\right)^{2}-\sum_{v \in V(T)} d_{2}(v / T)^{2} \\
& =\sum_{x_{i} \in N(u)-\left\{x_{1}, x_{2}=y_{1}\right\}}\left[\left(d_{2}\left(x_{i} / T^{\prime}\right)-1\right)^{2}-d_{2}\left(x_{i} / T\right)^{2}\right]-2 k-\alpha^{2}+3<0 .
\end{aligned}
$$


Case 3. $u$ is not a stem and $u y_{1} y_{2} \ldots y_{s}, u z_{1} z_{2} \ldots z_{t}, s, t \geq 2$, are two paths in $T$ such that $y_{1}=x_{1}$ and $z_{1}=x_{2}$.

Clearly $d_{2}(u / T)=\alpha+\beta-2, d_{2}\left(u^{\prime} / T\right)=k+\alpha-1$ for $k \geq \beta-1$ and $d_{2}\left(z_{t} / T\right)=$ $d_{2}\left(z_{t-1} / T\right)=1$. Let $T^{\prime}$ be the tree obtained from $T-u y_{1}$ by attaching the edge $z_{t} y_{1}$. Then $d_{2}\left(u^{\prime} / T^{\prime}\right)=k+\alpha-2, d_{2}\left(u / T^{\prime}\right)=\alpha+\beta-3$.

If $s=t=2$, then $d_{2}\left(y_{1} / T\right)=d_{2}\left(z_{1} / T\right)=\alpha-1, d_{2}\left(y_{2} / T\right)=d_{2}\left(y_{2} / T^{\prime}\right), d_{2}\left(y_{1} / T^{\prime}\right)=1$, $d_{2}\left(z_{1} / T^{\prime}\right)=\alpha-1, d_{2}\left(z_{2} / T\right)=1, d_{2}\left(z_{2} / T^{\prime}\right)=2$ and $d_{2}\left(x_{i} / T^{\prime}\right)=d_{2}\left(x_{i} / T\right)-1$ for $3 \leq i \leq \alpha-1$. Hence,

$$
\begin{aligned}
L M_{1}\left(T^{\prime}\right)-L M_{1}(T)= & \sum_{v \in V\left(T^{\prime}\right)} d_{2}\left(v / T^{\prime}\right)^{2}-\sum_{v \in V(T)} d_{2}(v / T)^{2} \\
= & \sum_{i=3}^{\alpha-1} d_{2}\left(x_{i} / T^{\prime}\right)^{2}+d_{2}\left(u^{\prime} / T^{\prime}\right)^{2}+d_{2}\left(u / T^{\prime}\right)^{2}+d_{2}\left(y_{1} / T^{\prime}\right)^{2}+d_{2}\left(z_{2} / T^{\prime}\right)^{2} \\
& \quad-\sum_{i=3}^{\alpha-1} d_{2}\left(x_{i} / T\right)^{2}-d_{2}\left(u^{\prime} / T\right)^{2}-d_{2}(u / T)^{2}-d_{2}\left(y_{1} / T\right)^{2}-d_{2}\left(z_{2} / T\right)^{2} \\
= & \sum_{i=3}^{\alpha-1}\left[\left(d_{2}\left(x_{i} / T\right)-1\right)^{2}-d_{2}\left(x_{i} / T\right)^{2}\right]+(\alpha+k-2)^{2}+(\alpha+\beta-3)^{2}+5 \\
& -(\alpha+k-1)^{2}-(\alpha+\beta-2)^{2}-1-(\alpha-1)^{2} \\
= & \sum_{i=3}^{\alpha-1}\left[\left(d_{2}\left(x_{i} / T\right)-1\right)^{2}-d_{2}\left(x_{i} / T\right)^{2}\right]-2 k-2 \beta-\alpha^{2}-2 \alpha+11<0 .
\end{aligned}
$$

Now, if $s=2$ and $t \geq 3$, then $d_{2}\left(y_{1} / T\right)=\alpha-1, d_{2}\left(z_{1} / T\right)=\alpha, d_{2}\left(y_{1} / T^{\prime}\right)=1, d_{2}\left(y_{2} / T\right)=$ $d_{2}\left(y_{2} / T^{\prime}\right)$ and $d_{2}\left(z_{1} / T^{\prime}\right)=\alpha-1, d_{2}\left(z_{t} / T^{\prime}\right)=d_{2}\left(z_{t-1} / T^{\prime}\right)=2$ and $d_{2}\left(z_{j} / T\right)=d_{2}\left(z_{j} / T^{\prime}\right)$ for $2 \leq j \leq t-2$. Therefore we have

$$
\begin{aligned}
L M_{1}\left(T^{\prime}\right)-L M_{1}(T)= & \sum_{v \in V\left(T^{\prime}\right)} d_{2}\left(v / T^{\prime}\right)^{2}-\sum_{v \in V(T)} d_{2}(v / T)^{2} \\
= & \sum_{i=3}^{\alpha-1} d_{2}\left(x_{i} / T^{\prime}\right)^{2}+d_{2}\left(u^{\prime} / T^{\prime}\right)^{2}+d_{2}\left(u / T^{\prime}\right)^{2}+d_{2}\left(y_{1} / T^{\prime}\right)^{2} \\
& \quad+d_{2}\left(z_{1} / T^{\prime}\right)^{2}+d_{2}\left(z_{t-1} / T^{\prime}\right)^{2}+d_{2}\left(z_{t} / T^{\prime}\right)^{2}-\sum_{i=3}^{\alpha-1} d_{2}\left(x_{i} / T\right)^{2} \\
& \quad-d_{2}\left(u^{\prime} / T\right)^{2}-d_{2}(u / T)^{2}-d_{2}\left(y_{1} / T\right)^{2} \\
& \quad-d_{2}\left(z_{1} / T^{\prime}\right)^{2}-d_{2}\left(z_{t-1} / T\right)^{2}-d_{2}\left(z_{t} / T\right)^{2} \\
= & \sum_{i=3}^{\alpha-1}\left[\left(d_{2}\left(x_{i} / T\right)-1\right)^{2}-d_{2}\left(x_{i} / T\right)^{2}\right]+(\alpha+k-2)^{2}+(\alpha+\beta-3)^{2} \\
& \quad+(\alpha-1)^{2}+9-(\alpha+k-1)^{2}-(\alpha+\beta-2)^{2}-\alpha^{2}-(\alpha-1)^{2}-2 \\
= & \sum_{i=3}^{\alpha-1}\left[\left(d_{2}\left(x_{i} / T\right)-1\right)^{2}-d_{2}\left(x_{i} / T\right)^{2}\right]-2 k-2 \beta-\alpha^{2}-4 \alpha+16<0 .
\end{aligned}
$$

Finally, let $s, t \geq 3$. Then $d_{2}\left(y_{1} / T\right)=d_{2}\left(z_{1} / T\right)=\alpha, d_{2}\left(y_{1} / T^{\prime}\right)=2$ and $d_{2}\left(z_{1} / T^{\prime}\right)=\alpha-1$. Also, $d_{2}\left(y_{i} / T\right)=d_{2}\left(y_{i} / T^{\prime}\right)$ for $2 \leq i \leq s, d_{2}\left(z_{t} / T^{\prime}\right)=d_{2}\left(z_{t-1} / T^{\prime}\right)=2$ and $d_{2}\left(z_{j} / T\right)=$ $d_{2}\left(z_{j} / T^{\prime}\right)$ for $2 \leq j \leq t-2$. Hence, 


$$
\begin{aligned}
L M_{1}\left(T^{\prime}\right)-L M_{1}(T)= & \sum_{v \in V\left(T^{\prime}\right)} d_{2}\left(v / T^{\prime}\right)^{2}-\sum_{v \in V(T)} d_{2}(v / T)^{2} \\
= & \sum_{i=3}^{\alpha-1} d_{2}\left(x_{i} / T^{\prime}\right)^{2}+d_{2}\left(u^{\prime} / T^{\prime}\right)^{2}+d_{2}\left(u / T^{\prime}\right)^{2}+d_{2}\left(y_{1} / T^{\prime}\right)^{2} \\
& \quad+d_{2}\left(z_{1} / T^{\prime}\right)^{2}+d_{2}\left(z_{t-1} / T^{\prime}\right)^{2}+d_{2}\left(z_{t} / T^{\prime}\right)^{2}-\sum_{i=3}^{\alpha-1} d_{2}\left(x_{i} / T\right)^{2} \\
& \quad-d_{2}\left(u^{\prime} / T\right)^{2}-d_{2}(u / T)^{2}-d_{2}\left(y_{1} / T\right)^{2} \\
& \quad-d_{2}\left(z_{1} / T^{\prime}\right)^{2}-d_{2}\left(z_{t-1} / T\right)^{2}-d_{2}\left(z_{t} / T\right)^{2} \\
= & \sum_{i=3}^{\alpha-1}\left[\left(d_{2}\left(x_{i} / T\right)-1\right)^{2}-d_{2}\left(x_{i} / T\right)^{2}\right]+(\alpha+k-2)^{2}+(\alpha+\beta-3)^{2} \\
& \quad+(\alpha-1)^{2}+9-(\alpha+k-1)^{2}-(\alpha+\beta-2)^{2}-\alpha^{2}-(\alpha-1)^{2}-2 \\
= & \sum_{i=3}^{\alpha-1}\left[\left(d_{2}\left(x_{i} / T\right)-1\right)^{2}-d_{2}\left(x_{i} / T\right)^{2}\right]-2 k-2 \beta-\alpha^{2}-6 \alpha+18<0 .
\end{aligned}
$$

By Lemma 1, among all trees of order $n$ with maximum degree $\Delta$, the spiders have the minimum first leap Zagreb index. In what follows, we determine the spiders having minimum first leap Zagreb index. If $\Delta=2$, then $T \cong P_{n}$. Therefore, let $\Delta \geq 3$.

Lemma 2. Let $T$ be a spider of order $n$ with $\Delta$ legs. If $T$ has two legs of length at least 3 , then there is a spider $T^{\prime}$ of order $n$ with $\Delta$ legs such that $L M_{1}\left(T^{\prime}\right)<L M_{1}(T)$.

Proof. Let $\omega$ be the center of $T$ and let $\omega x_{1} x_{2} \ldots x_{\ell}, \omega y_{1} y_{2} \ldots y_{t}, \ell, t \geq 3$, be two legs of length at least three in $T$. Let $T^{\prime}$ be the tree obtained from $T-x_{1} x_{2}$ by adding the edge $y_{t} x_{2}$, and let $d_{2}(\omega / T)=k$. Clearly $T^{\prime}$ is a spider of order $n$ with $\Delta$ legs. By definition we have,

$$
\begin{aligned}
L M_{1}\left(T^{\prime}\right)-L M_{1}(T) & =\sum_{v \in V\left(T^{\prime}\right)} d_{2}\left(v / T^{\prime}\right)^{2}-\sum_{v \in V(T)} d_{2}(v / T)^{2} \\
& =(k-1)^{2}-k^{2}+4-1+4-1+(\Delta-1)^{2}-\Delta^{2} \\
& =-2 k-2 \Delta+8<0 .
\end{aligned}
$$

Lemma 3. Let $T$ be a spider of order $n$ with $\Delta$ legs and let $\omega$ be the center of $T$ such that $d_{2}(w / T)=k$. If $T$ has a leg of length 2 and a leg of length at least 3 , then there is a spider $T^{\prime}$ of order $n$ with $\Delta$ legs such that $L M_{1}\left(T^{\prime}\right) \leq L M_{1}(T)$ with equality if and only if $k=2$.

Proof. Let $\omega x_{1} x_{2}$ be the leg of length 2 and $\omega y_{1} y_{2} \ldots y_{t}$ be the leg of length at least three in $T$. Let $T^{\prime}$ be the tree obtained from $T-x_{1} x_{2}$ by adding the edge $y_{t} x_{2}$. By definition we have

$$
\begin{aligned}
L M_{1}\left(T^{\prime}\right)-L M_{1}(T) & =\sum_{v \in V\left(T^{\prime}\right)} d_{2}\left(v / T^{\prime}\right)^{2}-\sum_{v \in V(T)} d_{2}(v / T)^{2} \\
& =(k-1)^{2}-k^{2}+4-1=-2 k+4 \leq 0 .
\end{aligned}
$$

The equality $L M_{1}\left(T^{\prime}\right)=L M_{1}(T)$ holds if and only if $d_{2}(\omega / T)=k=2$. 
Theorem 1. Let $T$ be a tree of order $n \geq 5$ with maximum degree $\Delta<(n-1) / 2$. Then $L M_{1}(T) \geq \Delta^{3}-2 \Delta^{2}-\Delta+4 n-10$, with equality if and only if $T$ is a spider whose $T$ has exactly one leg of length at least three and at most one leg of length two.

Proof. Let $T_{1}$ be a tree of order $n \geq 5$ with maximum degree $\Delta<(n-1) / 2$ such that

$L M_{1}\left(T_{1}\right)=\min \left\{L M_{1}(T) \mid T\right.$ is a tree of order $n$ with maximum degree $\left.\Delta<(n-1) / 2\right\}$.

Let $v$ be a vertex with maximum degree $\Delta$. Root $T_{1}$ at $v$. By the choice of $T_{1}$, we deduce from Lemma 1 that $T_{1}$ is a spider with center $v$. Since $\Delta<(n-1) / 2$, then $T_{1}$ has at least one leg of length at least three. It follows from Lemmas 2,3 , and the choice of $T_{1}$ that $T_{1}$ has exactly one leg of length at least three and at most one leg of length two. Then $L M_{1}\left(T_{1}\right)=$ $\Delta^{3}-2 \Delta^{2}-\Delta+4 n-10$.

If $T$ is a spider with exactly one leg of length at least three and at most one leg of length two, then $L M_{1}(T)=4 n+\Delta^{3}-2 \Delta^{2}-\Delta-10$, and if $T^{\prime}$ is a spider whose all legs have length at most two, then $L M_{1}\left(T^{\prime}\right)=n^{2}+\Delta^{3}-\Delta^{2}+2 \Delta-2 n \Delta-n$. Therefore

$$
L M_{1}(T)-L M_{1}\left(T^{\prime}\right)=-(n-\Delta)^{2}+3(n-\Delta)+2 n-10 .
$$

Let $x=n-\Delta$ and $f(x)=-x^{2}+3 x+2 n-10$. Then

$$
f(x)>0, \quad \text { when }(3-\sqrt{8 n-31}) / 2<x<(3+\sqrt{8 n-31}) / 2,
$$

and

$$
f(x)<0, \quad \text { when } x<(3-\sqrt{8 n-31}) / 2 \text { or } x>(3+\sqrt{8 n-31}) / 2 .
$$

If $n \geq 5$, then since $x$ is positive integer number, we can see that $x \neq(3-\sqrt{8 n-31}) / 2$. In other words, by equation (1), we have

$$
\begin{gathered}
L M_{1}(T)>L M_{1}\left(T^{\prime}\right), \quad \text { when } \frac{2 n-3-\sqrt{8 n-31}}{2}<\Delta<\frac{2 n-3+\sqrt{8 n-31}}{2}, \\
L M_{1}\left(T^{\prime}\right)>L M_{1}(T), \text { when } \Delta>\frac{2 n-3+\sqrt{8 n-31}}{2} \text { or } \Delta<\frac{2 n-3-\sqrt{8 n-31}}{2},
\end{gathered}
$$

and

$$
L M_{1}(T)=L M_{1}\left(T^{\prime}\right), \quad \text { when } \quad \Delta=\frac{2 n-3-\sqrt{8 n-31}}{2} .
$$

Using an argument similar to that described in proof of Theorem 1 and equations (2), (3), (4), we obtained the next results.

Theorem 2. Let $T$ be a tree of order $n \geq 8$ with maximum degree

$$
\frac{n-1}{2} \leq \Delta<\frac{2 n-3-\sqrt{8 n-31}}{2} \text { or } \quad \Delta \geq \frac{2 n-3+\sqrt{8 n-31}}{2} .
$$

Then $L M_{1}(T) \geq 4 n+\Delta^{3}-2 \Delta^{2}-\Delta-10$, with equality if and only if $T$ is a spider whose $T$ has exactly one leg of length at least three and at most one leg of length two. 
Theorem 3. Let $T$ be a tree of order $n \geq 8$ with maximum degree

$$
\frac{2 n-3-\sqrt{8 n-31}}{2}<\Delta \leq \frac{2 n-3+\sqrt{8 n-31}}{2} .
$$

Then $L M_{1}(T) \geq n^{2}+\Delta^{3}-\Delta^{2}+2 \Delta-2 n \Delta-n$, with equality if and only if $T$ is a spider whose all legs have length at most two.

In Figures 1-3 six trees of orders $n=10,12$ with maximum degree $\Delta=5,6$ and with minimum first leap Zagreb index are illustrated.

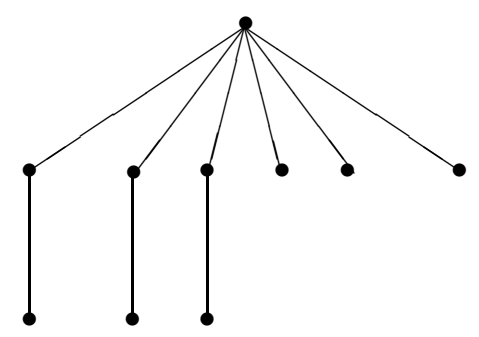

Fig. 1. The tree with $n=10, \Delta=6$ and $L M_{1}(T)=162$.
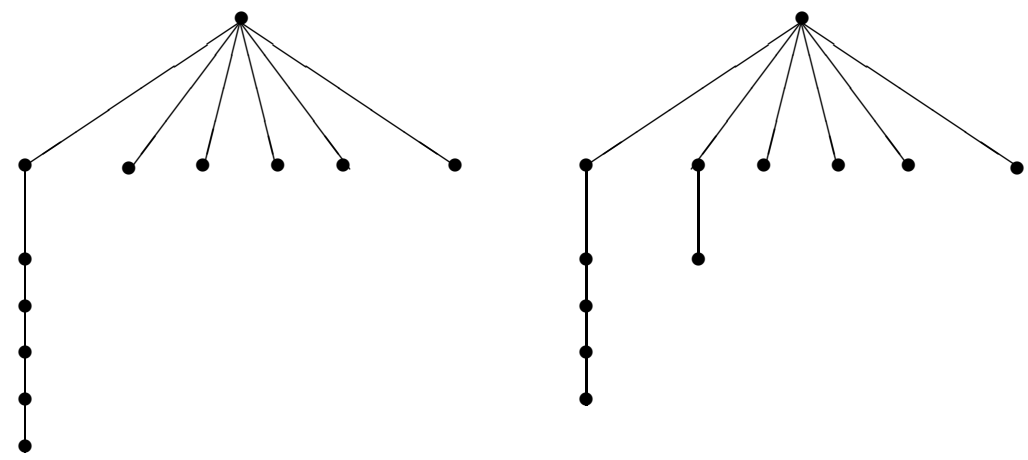

Fig. 2. Trees with $n=12, \Delta=6$ and $L M_{1}(T)=176$.
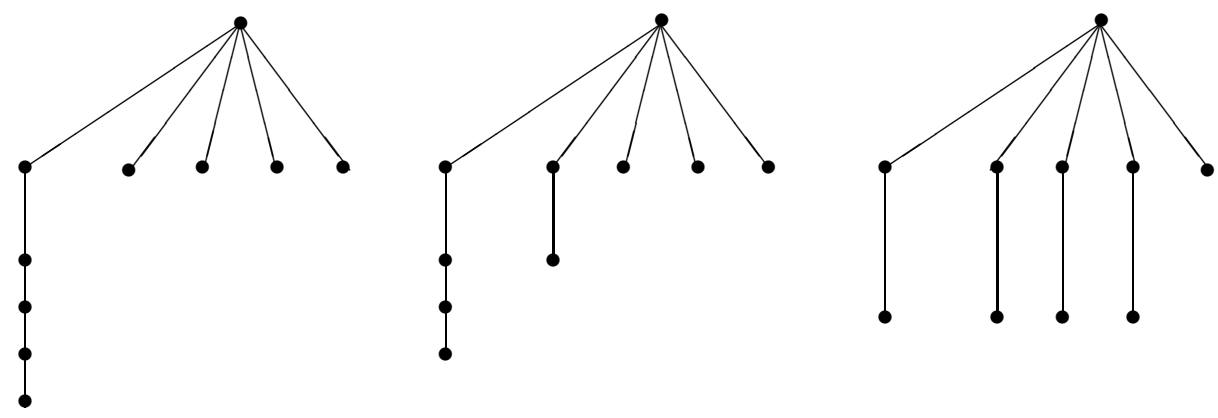

Fig. 3. Trees with $n=10, \Delta=5$ and $L M_{1}(T)=100$.

R. Rasi et al. [19], proved the following upper bound for the first Zagreb index of trees. They also characterized the corresponding extremal trees. 
Theorem 4. Let $T$ be a tree of order $n$ and maximum degree $\Delta$. If $n \equiv r(\bmod \Delta-1)$, then

$$
M_{1}(T) \leq \begin{cases}(\Delta+2) n-4 \Delta+4, & r=0 \\ (\Delta+2) n-3 \Delta, & r=1 \\ (\Delta+2) n-2 \Delta-2, & r=2 \\ (\Delta+2) n-2 \Delta-3+r(r-2), & r \geq 3\end{cases}
$$

A.M. Naji et al. [17], proved the following result.

Theorem 5. Let $G$ be a connected graph with $n$ vertices and $m$ edges. Then $L M_{1}(G) \leq$ $M_{1}(G)+n(n-1)^{2}-4 m(n-1)$. Equalities hold if and only if the diameter of $G$ is at most two.

The next result is an immediate consequence of Theorems 4 and 5.

Corollary 1. Let $T$ be a tree of order $n$ and maximum degree $\Delta$. If $n \equiv r(\bmod \Delta-1)$, then

$$
L M_{1}(T) \leq \begin{cases}(\Delta+2) n-4 \Delta+4+(n-4)(n-1)^{2}, & r=0 \\ (\Delta+2) n-3 \Delta+(n-4)(n-1)^{2}, & r=1 \\ (\Delta+2) n-2 \Delta-2+(n-4)(n-1)^{2}, & r=2 \\ (\Delta+2) n-2 \Delta-3+r(r-2)+(n-4)(n-1)^{2}, & r \geq 3 .\end{cases}
$$

\section{References}

[1] Ali A., Raza Z., Bhatti A.A. On the augmented Zagreb index. Kuwait J. Sci. 2016, 43 (2), 48-63.

[2] Alwardi A., Alqesmah A., Rangarajan R., Cangul I.N. Entire Zagreb indices of graphs. Discrete Math. Algorithms Appl. 2018, 10 (3), 1850037. doi:10.1142/S1793830918500374

[3] Ashrafi A., Došlić T., Hamzeh A. The Zagreb coindices of graph operations. Discrete Appl. Math. 2010, 158 (15), 1571-1578. doi:10.1016/j.dam.2010.05.017

[4] Borovicanin B., Das K.C., Furtula B., Gutman I. Bounds for Zagreb indices. MATCH Commun. Math. Comput. Chem. 2017, 78 (1), 17-100.

[5] Dehgardi N. A note on revised Szeged index of graph operations. Iran. J. Math. Chem. 2018, 9 (1), 57-63. doi:10.22052/ijmc.2017.58647.1228

[6] Dehgardi N., Aram H. Sharp bounds on the augmented Zagreb index of graph operations. Kragujevac J. Math. 2020, 44 (4), 509-522. doi:10.46793/kgjmat2004.509d

[7] Dehgardi N., Azari M. More on Mostar index. Appl. Math. E-Notes 2020, 20, 316-322.

[8] Dehgardi N., Liu J.-B. Lanzhou index of trees with fixed maximum degree. MATCH Commun. Math. Comput. Chem. 2021, 86 (1), 3-10.

[9] Došlić T. Vertex-weighted Wiener polynomials for composite graphs. Ars Math. Contemp. 2008, 1 (1), 66-80. doi:10.26493/1855-3974.15.895

[10] Došlić T., Martinjak I., Škrekovski R., Spužević S.T., Zubac I. Mostar index. J. Math. Chem. 2018,56 (10), 2995-3013. doi:10.1007/s10910-018-0928-z

[11] Furtula B., Graovac A., Vukičević D. Augmented Zagreb index. J. Math. Chem. 2010, 48 (2), $370-380$. doi:10.1007/s10910-010-9677-3

[12] Gutman I., Dehgardi N., Aram H. On general first Zagreb index of graphs with fixed maximum degree. Bull. Int. Math. Virtual Inst. 2016, 6 (2), 251-258. 
[13] Gutman I., Furtula B., Vukičević K., Popivoda G. On Zagreb indices and coindices. MATCH Commun. Math. Comput. Chem. 2015, 74 (1), 5-16.

[14] Gutman I., Milovanović E., Milovanović I. Beyond the Zagreb indices. AKCE Int. J. Graphs Comb. 2020, 17 (1), 74-85. doi:10.1016/j.akcej.2018.05.002

[15] Gutman I., Trinajstić N. Graph theory and molecular orbitals. Total $\pi$-electron energy of alternant hydrocarbons. Chem. Phys. Lett. 1972, 17 (4), 535-538. doi:10.1016/0009-2614(72)85099-1

[16] Luo L., Dehgardi N., Fahad A. Lower bounds on the entire Zagreb indices of trees. Discrete Dyn. Nat. Soc. 2020, 2020, 8616725. doi:10.1155/2020/8616725

[17] Naji A.M., Soner N.D., Gutman I. On leap Zagreb indices of graphs. Commun. Comb. Optim. 2017, 2 (2), 99-117. doi:10.22049/cco.2017.25949.1059

[18] Randić M. On generalization of Wiener index for cyclic structures. Acta Chim. Slov. 2002, 49, 483-496.

[19] Rasi R., Sheikholeslami S.M., Behmaram A. An upper bound on the first Zagreb index and coindex in trees. Iran. J. Math. Chem. 2017, 8 (1), 71-82. doi:10.22052/ijmc.2017.42995

[20] Shao Z., Gutman I., Li Z., Wang S., Wu P. Leap Zagreb indices of trees and unicyclic graphs. Commun. Comb. Optim. 2018, 3 (2), 179-194. doi:10.22049/cco.2018.26285.1092

[21] Vukičević D., Li Q., Sedlar J., Došlić T. Lanzhou Index. MATCH Commun. Math. Comput. Chem. 2018, 80 (3), 863-876.

[22] Zhu J.-M., Dehgardi N., Li X. The third leap Zagreb index for trees. J. Chem. 2019, 2019, article ID 9296401. doi:10.1155/2019/9296401

Received 31.10.2020

Revised 16.01.2021

Аегарді Н., Арам Г. Межі для індексу Загреба першого стрибка дерев // Карпатські матем. публ. — 2021. — T.13, №2. - С. 377-385.

Індекс Загреба першого стрибка $L M 1(G)$ графра $G$ - це сума квадратів степенів його других вершин, тобто $L M_{1}(G)=\sum_{v \in V(G)} d_{2}(v / G)^{2}$, де $d_{2}(v / G)$ - це кількість других сусідів $v$ у $G$. У цій роботі отримано межі для індексу Загреба першого стрибка дерев та визначено екстремальні дерева, які досягають цих меж.

Ключові слова і фрази: дерево, індекс Загреба першого стрибка, індекс Загреба. 